\title{
Term Pregnancy in a Patient with Septate Uterus: Incidental Finding at Caesarean Section
}

\author{
Adebiyi G. Adesiyun, Solomon Avidime, Hajaratu Umar, Ranyang Akafa, Rabi'at Aliyu \\ Department of Obstetrics \& Gynaecology, Ahmadu Bello University Teaching Hospital, Zaria, Nigeria \\ Email: biyi.adesiyun@yahoo.com
}

Received 18 December 2013; revised 17 January 2014; accepted 15 February 2014

Copyright (C) 2014 by authors and Scientific Research Publishing Inc.

This work is licensed under the Creative Commons Attribution International License (CC BY). http://creativecommons.org/licenses/by/4.0/

(c) (i) Open Access

\begin{abstract}
Mullerian duct anomalies are the most common congenital anomalies of the reproductive system and septate uterus is the most frequently diagnosed Müllerian anomaly. The true incidence of Mullerian duct anomalies is difficult to state because some cases may be asymptomatic and there are pitfalls associated with various diagnostic methods. This is a case report of a 17-year-old primigravida with septate uterus diagnosed at caesarean section performed at term for cephalo-pelvic disproportion. Baby was delivered with bilateral talipes equinovarus.
\end{abstract}

\section{Keywords}

Undiagnosed; Septate Uterus; Term Pregnancy; Talipes Equinovarus

\section{Introduction}

Congenital uterine anomalies caused by Müllerian fusion defects are the most common congenital anomalies of the reproductive system and septate uterus is the most common Müllerian anomaly, occurring in $2 \%-3 \%$ of women [1]. It can be categorized into partial (subseptate) or complete septate groups [2]. It is associated with poor reproductive outcomes from factors such as recurrent spontaneous abortion, stillbirth and preterm birth resulting in fetal survival rate of $6 \%-28 \%$ and a high rate of spontaneous abortion as high as $60 \%$ [3]. Some researchers advocate surgical treatment for all women with septate uterus, including those who do not have a history of repeated adverse reproductive outcome [1]. This case illustrates that septate uterus may be associated with good reproductive outcome, although baby was born with positional limb deformity. 


\section{Case Report}

Mrs. N.L was a 17-year-old primigravida who conceived the index pregnancy spontaneously. She booked the index pregnancy at 28 weeks gestation at a primary health centre and the antenatal period was uneventful. Her past medical history was not significant. A routine obstetric ultrasound scan was not done through out the pregnancy. She presented to our facility with term pregnancy and in labour. The findings on abdominal examination were a symphysio-fundal height of $43 \mathrm{~cm}$. There was a single foetus in longitudinal lie and cephalic presentation. The descent was $4 / 5$ palpable per abdomen and the foetal heart rate was 144 beats per minutes. The clinical estimated foetal weight was $3100 \mathrm{~g}$. Vaginal examination revealed a cervical dilatation of $4 \mathrm{~cm}$ with a compromised mid cavity on pelvic assessment. She later had an emergency lower segment ceasarean section on account of cephalo-pelvic disproportion and was delivered of a live female infant whose weight was $2750 \mathrm{~g}$ with bilateral talipes equinovarus deformity (Figure 1).

Uterine septum that extends to the level of lower segment uterine incision was discovered after the delivery of the placenta (Figure 2) and the serosa surface of the uterus show indentation commensurate to the septal area (Figure 3).

\section{Discussion}

A uterine septum is a form of a congenital malformation where the uterine cavity is partitioned by a longitudinal septum. Mainly the serosa surface of the uterus has a normal typical shape. However, a groove-like induration was noticed in this case. The wedge-like partition may involve only the superior part of the cavity resulting in an incomplete septum or a subseptate uterus, or less frequently the total length of the cavity (complete septum) and the cervix resulting in a double cervix. A subseptate variety was found in this patient. The septation may also continue caudally into the vagina resulting in a double vagina [4]. The structurally anomalous uterus has long been

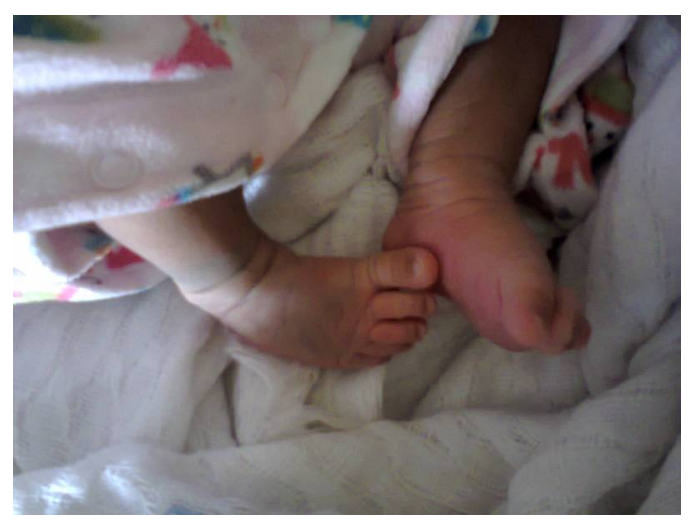

Figure 1. Fetal feet showing talipes equinovarus.

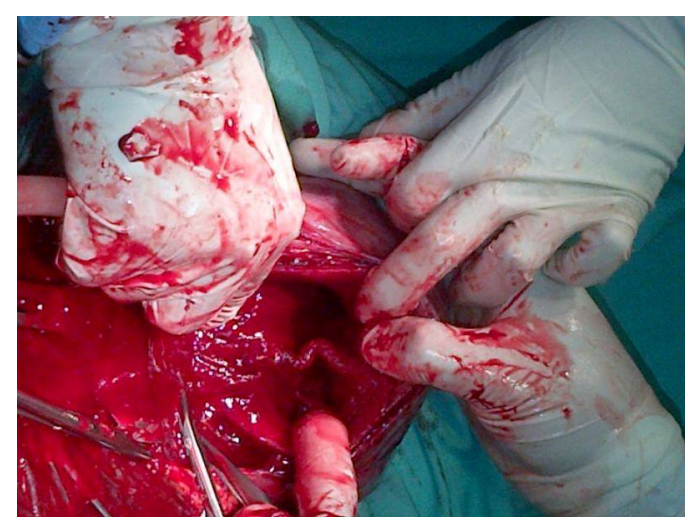

Figure 2. Intrauterine septum extending to the lower part of the uterine body. 


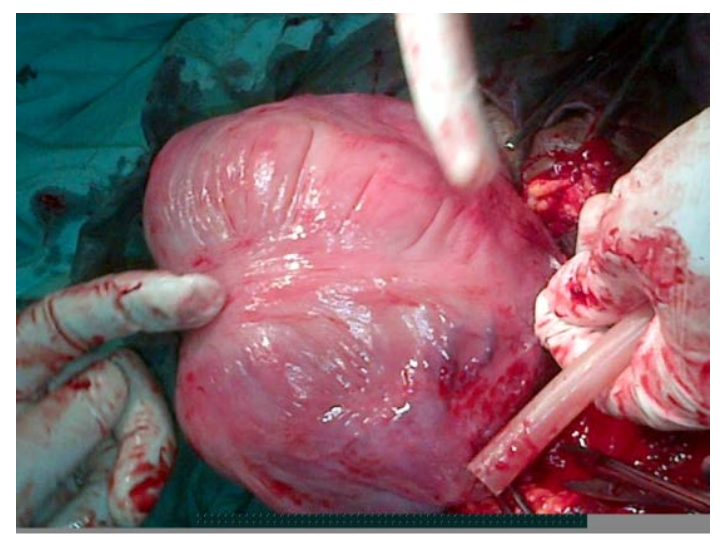

Figure 3. Groove on the serosal surface of the uterus commensurate with the intrauterine septum location.

recognized as a cause of obstetric complications. Congenital malformations may be associated with recurrent pregnancy loss, preterm labour, abnormal fetal presentation, and Infertility [5]. The patient presented did not experience any of these complications.

The condition may not be known to the affected individual and may not result in any reproductive problems; thus normal pregnancies may occur [6], as it is for the case being presented. Transvaginal 3-dimensional ultrasonography appears to be extremely accurate for the diagnosis and classification of congenital uterine anomalies, more than office hysteroscopy and magnetic resonance imaging [7]. It may conveniently become the only mandatory step in the assessment of the uterine cavity in patients with a suspected septate or bicornuate uterus [7]. However, Mrs N.L did not have the benefit of an ultrasound scan during pregnancy that might have suggested this diagnosis. If she had had an obstetric ultrasound scan, it would likely have been with a two-dimensional ultrasound machine which is reported to be associated with low precision in differentiating between arcuate, bicornuate and septate anomaly due to restricted view and assesment of the uterine fundus [8] [9]. This patient carried the pregnancy to term, which is not surprising because longer uterine septa as found in this patient is reported to have increased vascularity and thus supports pregnancy better [10].

The place of surgery is conjectural. Some authors' belief is that septum should not be removed if detected in asymptomatic patient undergoing routine evaluation for infertility or non-infertility related indications. On the other side, some authors believe that it is not reasonable to expose infertility patients with septum to high risk of miscarriage when she finally gets pregnant [11] [12]. However, there is a consensus of opinion that surgery should be done when septate uterus is detected in women with recurrent pregnancy loss. Hysteroscopic septoplasty is highly favoured procedure resulting in low morbidity and improvement in pregnancy outcomes [13] [14]. In this case, we did not contemplate removing the septum because the caesarean section was an emergent intrapartum one with likelihood of genital sepsis that may complicate healing. The effect of undiagnosed uterine septum was seen in the baby of the patient and thus she may have benefitted from surgical intervention if diagnosed before conception. The baby was referred to the orthopaedic surgeons for management.

\section{References}

[1] Pang, L.-H., Li, M.-J., Li, M.Q., Xu, H. and Wei, Z.-L. (2011) Not Every Subseptate Uterus Requires Surgical Correction to Reduce Poor Reproductive Outcome. International Journal of Gynecology \& Obstetrics, 115, 260-263. http://dx.doi.org/10.1016/j.ijgo.2011.07.030

[2] The American Fertility Society (1988) Classifications of Adnexal Adhesions, Distal Tubal Occlusion, Tubal Occlusion Secondary to Tubal Ligation, Tubal Pregnancies, Müllerian Anomalies and Intrauterine Adhesions. Fertility and Sterility, 49, 944-955.

[3] Zlopasa, G., Skrablin, S., Kalafatić, D., Banović, V. and Lesin, J. (2007) Uterine Anomalies and Pregnancy Outcome Following Resectoscope Metroplasty. International Journal of Gynecology \& Obstetrics, 98, 129-133. http://dx.doi.org/10.1016/j.ijgo.2007.04.022

[4] Heinonen, P.K. (2006) Complete Septate Uterus with Longitudinal Vaginal Septum. Fertility and Sterility, 85, 700-705. http://dx.doi.org/10.1016/j.fertnstert.2005.08.039 
[5] Raga, F., Bauset, C., Remohi, J., Bonilla-Musoles, F., Simon, C. and Pellicer, A. (1997) Reproductive Impact of Congenital Müllerian Anomalies. Human Reproduction, 12, 2277-2281. http://dx.doi.org/10.1093/humrep/12.10.2277

[6] Creasy, R.K. and Resnik, R. (1994) Maternal-Fetal Medicine: Principles and Practice. W.B. Saunders, Philadelphia 447.

[7] Faivre, E., Fernandez, H., Deffieux, X., Gervaise, A., Frydman, R. and Levaillant, J.M. (2012) Accuracy of ThreeDimensional Ultrasonography in Differential Diagnosis of Septate and Bicornuate Uterus Compared with Office Hysteroscopy and Pelvic Magnetic Resonance Imaging. Journal of Minimally Invasive Gynecology, 19, 101-106. http://dx.doi.org/10.1016/j.jmig.2011.08.724

[8] Nicolini, U., Bellotti, M., Bonazzi, B., Zamberletti, D. and Candiani, G.B. (1987) Can Ultrasound Be Used to Screen Uterine Malformations? Fertility and Sterility, 47, 89-93.

[9] Pellerito, J.S., McCarthy, S.M., Doyle, M.B., Glickman, M.G. and DeCherney, A.H. (1992) Diagnosis of Uterine Anomalies: Relative Accuracy of MR Imaging, Endovaginal Sonography and Hysterosalpingography. Radiology, 183, 795-800.

[10] Dabirashafi, H., Bahadori, S., Mohammed, K., Alavi, M., Moghadami-Tabrizi, N., Zandinejad, K., et al. (1995) Septate Uterus: New Idea on the Histological Features of the Sepyum in This Abnormal Uterus. American Journal of Obstetrics \& Gynecology, 171, 105-107. http://dx.doi.org/10.1016/0002-9378(95)90093-4

[11] Balen, A.H. (2008) Tubal Infertility and Fibroid. In: Infertility in Practice, Informa, London, 239-257. http://dx.doi.org/10.3109/9781439807224.011

[12] Ozgur, K., Isikoglu, M., Donmez, L. and Oehninger, S. (2007) Is Hysteroscopic Correction of an Incomplete Uterine Septum Justified Prior to IVF? Reproductive BioMedicine Online, 14, 335-340. http://dx.doi.org/10.1016/S1472-6483(10)60876-0

[13] Homer, H.A., Li, T.C. and Cooke, I.D. (2000) The Septate Uterus: A Review of Management and Reproductive Outcome. Fertility and Sterility, 73, 1-14. http://dx.doi.org/10.1016/S0015-0282(99)00480-X

[14] Propst, A.M. and Hill, J.A. (2000) Anatomic Factors Associated with Pregnancy Loss. Seminars in Reproductive Medicine, 18, 341-350. http://dx.doi.org/10.1055/s-2000-13723 